\title{
Morphology and Structure of Ring-banded Spherulites Obtained by Solvent Evaporation in PLLA/PAAC Blend Films
}

\author{
By Yongxin LI, Xincai LIU, Danming CHAO, Lili CUI, and Wanjin ZHANG*
}

KEY WORDS: Poly(L-lactic acid) / Electroactive Polyamide / Ring-banded Spherulites /

Poly(L-lactic acid) (PLLA) has been attracting much attention for its biodegradability, high drug permeability and biocompatibility. ${ }^{1-3}$ The crystallization and morphology of PLLA have been extensively investigated. ${ }^{4-7}$ It was reported that the common non-banded spherulites with simple extinction crosses were obtained during isothermal crystallization after fast cooling from the melt. However, after blending with a compatible polymer, such as atactic poly(3-hydroxybutyrate), ${ }^{8,9}$ poly(ethylene glycol), ${ }^{10,11}$ and poly(ethylene oxide), ${ }^{12}$ PLLA can form banded spherulites crystallized from the melt.

Banded spherulites are commonly observed under polarized optical microscope in semicrystalline polymers and polymer blends, and banding in polymers has been studied for a long time. ${ }^{13-20}$ It is generally believed that the basic mechanism leading to the extinction bands should be periodic twisting of lamellae along the radial growth direction of the spherulites under the influence of surface stress. ${ }^{13,21,22}$ However, the twisting of lamellar crystals might not be the only reason for the formation of ring-banded structures. In the 1950s, Keith and Padden found the same concentric rings in polyethylene spherulites under an unpolarized configuration and proposed that the formation of ring-banded structures was attributed to structural discontinuities caused by rhythmic crystal growth. The past ten years, rhythmic crystal growth mechanism was gradually proved by large numbers of experiment. ${ }^{23-26}$ In 2004 , Schultz et al. reported that depletion of material at the growth front, due to the specific volume decrement between crystal and melt, in melt-crystallized isotactic polystyrene thin films, resulted in nonbirefringent banded hedritic structures. ${ }^{27}$ In 2007, a nonlinear diffusion process induced rhythmic growth based on periodically changing concentration gradient in the polymer solution was proposed. ${ }^{28}$

Recently, we have successfully synthesized a new kind of electroactive polyamide that has alternating conjugated segment (amine-capped aniline pentamer) and nonconjugated segment in the main chain. ${ }^{29}$ In this work, by controlling the solvent evaporation rate, we have obtained concentric ringbanded structures in thin films of poly(L-lactic acid) and the electroactive polyamide blends, and the crystallization mechanism has been studied.

\section{EXPERIMENTAL}

\section{Materials}

Poly(L-lactic acid) (PLLA) was kindly supplied by State Key Laboratory of Polymer Physics and Chemistry, Changchun Institute of Applied Chemistry. The numberaverage molecular weight of PLLA is about 30000 , with a polydispersity of 1.6 . Its melting temperature was measured to be $169^{\circ} \mathrm{C}$.

A new kind of electroactive polyamide with amine-capped aniline pentamer in the main chain (PAAC) was synthesized by oxidative coupling polymerization as described in our previous article. ${ }^{29,30}$ Figure 1 shows its chemical structure. Its $\mathrm{Mn}$ is 29000 , with a polydispersity of 1.9 .

\section{Sample Preparation and Instruments}

PLLA/PAAC blends were dissolved in $N, N$-dimethylformamide (DMF), stirring for at least $12 \mathrm{~h}$ at room temperature, to produce solution with different concentration. When use, the solution and cleaned substrates (glass slides), was heated to crystallization temperature for a certain time on a hot stage. Then one droplet of solution $(5 \mu \mathrm{L})$ was cast onto the substrates with a close vessel covering on it. Under these conditions, solvent can only escape through the small gap between the cover and the hot stage. A certain air pressure existed above the surface of the film during the whole process of crystallization. The solvent evaporation rate was controlled by using vessels with different volume which can be calculated. A solvent evaporation rate of $2.8 \mu \mathrm{L} / \mathrm{min}$ was achieved by using a vessel with volume of $95.0 \mathrm{~cm}^{3}$. After the solvent was completely volatilized, the films were cooled to room temperature slowly and then were used directly for optical microscopic observations.

The tetrahydrofuran (THF) solvent, which can only dissolve the PLLA in the blends, was selected for solvent washing experiment. The blend films supported by substrates (glass slides) etched in the THF for $20 \mathrm{~min}$. The etched films were observed under AFM after the solvent was completely volatilized.

The PLM observations of the thin films were performed using a Leica DM-LP microscope equipped with a CCD 


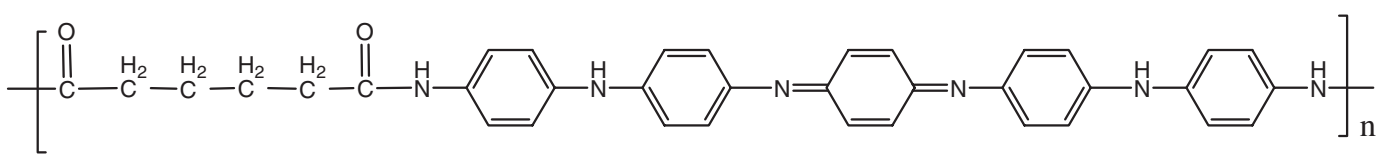

Figure 1. The chemical structure of PAAC.

camera. The AFM studies were performed with a SPM-9500 J2 atomic force microscope, the contact mode was used to obtain height images. Thermal analysis was performed using a Mettler Toledo differential scanning calorimeter (DSC821 ${ }^{\mathrm{e}}$ ). Samples for DSC analysis were initially annealed at $180^{\circ} \mathrm{C}$ for $3 \mathrm{~min}$ to destroy any thermal history, followed by quenching them to liquid nitrogen. Following this, the samples were heated at a rate of $10^{\circ} \mathrm{C} / \mathrm{min}$ under nitrogen atmosphere with a flow rate of $100 \mathrm{~cm}^{3} / \mathrm{min}$ to evaluate the glass transition temperatures and melting point temperatures of the blends.

\section{RESULTS AND DISCUSSION}

\section{Thermal Behavior of the PLLA/PAAC Blends}

The thermal behavior of the PLLA/PAAC blends was characterized by DSC. Figure 2 shows the DSC traces of PLLA/PAAC blends after melt quenching at a scanning rate of $10^{\circ} \mathrm{C} / \mathrm{min}$. Each of the PLLA/PAAC blends only exhibits a single composition dependent $T_{\mathrm{g}}$. We can conclude that PLLA and PAAC are miscible when the content of PAAC is not more than $20 \mathrm{wt} \%$ in the blends.

\section{Ring-banded Spherulites in PLLA/PAAC Blends}

By controlling the solvent evaporation rate during polymer solution casting, we have obtained concentric ring-banded structures in the PLLA/PAAC blends. Figure 3 shows the PLM images of concentric ring-banded spherulites formed at the solvent evaporation rate of $2.8 \mu \mathrm{L} / \mathrm{min}$ from 3-wt. \% DMF solution at $130{ }^{\circ} \mathrm{C}$ in the PLLA/PAAC blends.

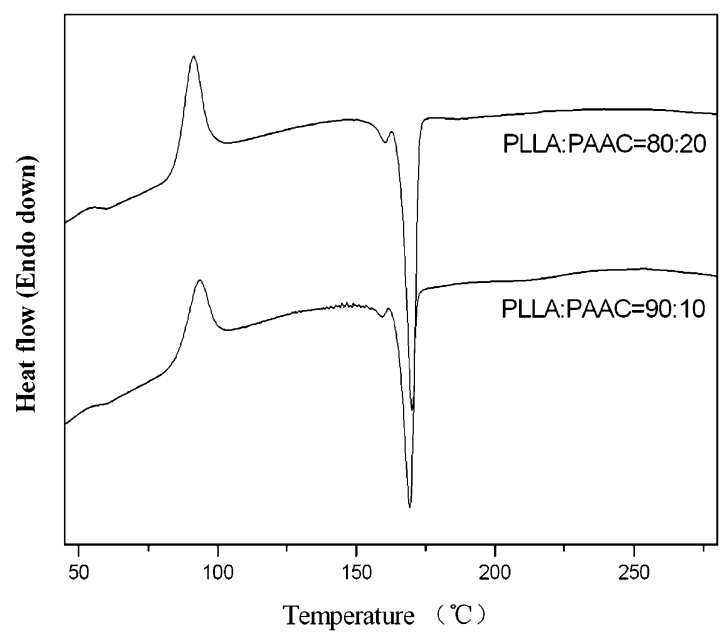

Figure 2. DSC traces of PLLA/PAAC blends after melt quenching at a scanning rate of $10^{\circ} \mathrm{C} / \mathrm{min}$.
The ring-banded structure can also be examined with AFM. A typical AFM topography image is shown in Figure 4a. The brightness contrast of the alternating bright and dark bands is attributed to height contrast. The banded structure observed by AFM is similar to the alternate bright and dark bands observed by PLM. The width of the bands is $10-20 \mu \mathrm{m}$ and the diameter of the ring-banded spherulites is about $100 \mu \mathrm{m}$. The AFM height trace (Figure 4b) shows that the vertical distance between the lowest and the highest points on the sample surface (band height amplitude) ranges from 270 to $330 \mathrm{~nm}$.

To identify the material composition in both the light (ridge) and dark (valley) regions of the ring-banded spherulites, a solvent washing experiment was carried out. Tetrahydrofuran (THF), which can only dissolve PLLA in the blends, was chosen as the washing solvent. Figure 5a shows the AFM image of the etched ring-banded spherulites in the 90:10 PLLA/PAAC blend. After etched, the concentric bright and dark bands are also observed. But the surface fluctuation of the ring-banded spherulites is obviously lower than that before etched. The vertical distance between the lowest and the highest points on the sample surface changes to from 150 to $250 \mathrm{~nm}$. This height change is because PLLA is dissolved in THF. So we can conclude that in Figure 4a the bright rings are mainly composed of the PLLA phase (which could be washed out by the solvent and cause the height change), while PAAC mainly exists in the dark rings. ${ }^{31}$

\section{Crystallization Mechanism of Ring-banded Spherulites Formation}

Pure PLLA was also crystallized at the solvent evaporation rate of $2.8 \mu \mathrm{L} / \mathrm{min}$ from 3 -wt. \% DMF solution at $130{ }^{\circ} \mathrm{C}$, and the common non-banded spherulites with simple extinction crosses were observed under PLM. Therefore, the presence of noncrystallizing component PAAC played an important role on morphology in the blends.

During the solvent evaporation process, the concentration of both component increased gradually. Because of the bad solubility, some of PAAC deposited first from the solution, and congregated to form a nucleus of the ring-banded spherulites. Then the crystallizing component PLLA crystallized around the PAAC core, and formed the first ring. At the same time, PAAC molecular chains were rejected away from crystallization region, forming the PAAC-rich regions (the first dark region) outside the PLLA ring. Repeating the rhythmic growth process, PLLA grew to form the ridge and PAAC was rejected and accumulated in the valley regions. The ring-banded spherulites structure was formed.

To be noted, the ring-banded spherulites structure can not be observed in the 90:10 PLLA/PAAC blend during isothermal 

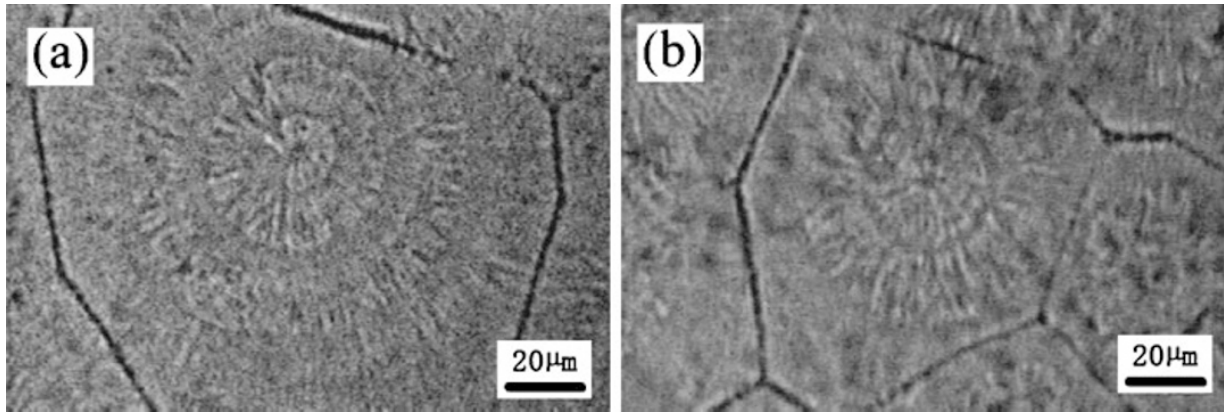

Figure 3. PLM images of thin films of the 90:10 (a) and 80:20 (b) PLLA/PAAC blends heat-treated at $130^{\circ} \mathrm{C}$ at the solvent evaporation rate of $2.8 \mu \mathrm{L} / \mathrm{min}$.

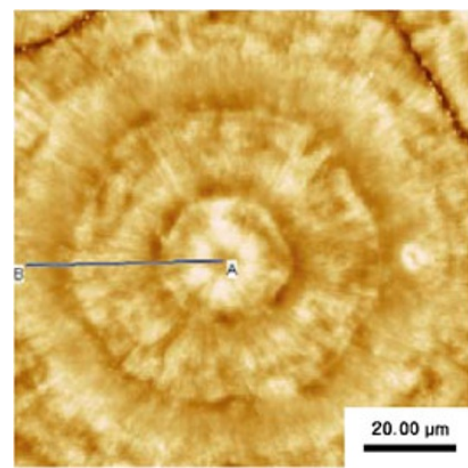

(a)

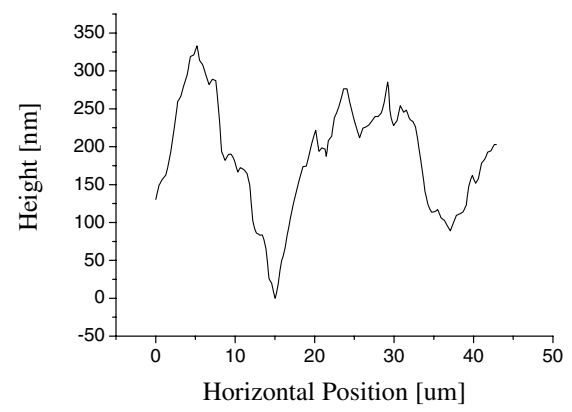

(b)

Figure 4. (a) AFM height image of ring-banded spherulites in thin films of the 90:10 PLLA/PAAC blend. (b) a through A-B height trace.

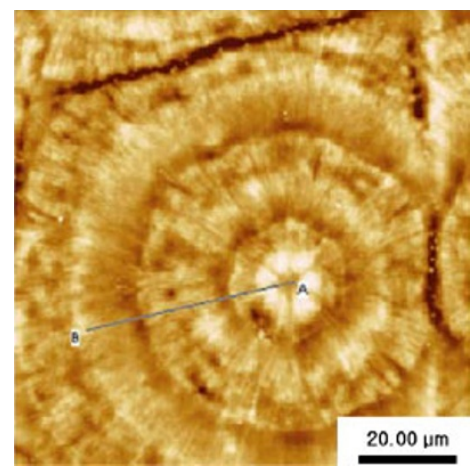

(a)

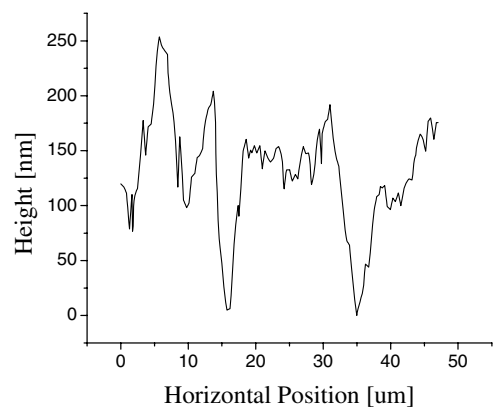

(b)

Figure 5. (a) AFM height image of the etched ring-banded spherulites in thin films of the 90:10 PLLA/PAAC blend. (b) a through A-B height trace.

crystallization after fast cooling from the melt. Because the movement capability of PAAC in the solidification state was worse than in the solution, PAAC can not be rejected effectively away from crystallization region and accumulate in the valley regions. In addition, solvent evaporation rate also has a significant effect on the formation of the ring-banded spherulites. ${ }^{28}$ The blends can form the ring-banded spherulites in a narrow solvent evaporation rate range. At lower solvent evaporation rate, the authors think, the abundance PAAC around the crystallization front may diffuse away to the far field, the PAAC-rich regions can not be formed. And at higher solvent evaporation rate, the crystallization rate is too fast.
The polymer chains have no enough time to transport, and accumulate locally. The ring-banded spherulites can not be formed. The effect of solvent evaporation rate on the spherulites morphology is still under a further research.

\section{CONCLUSION}

By controlling the solvent evaporation rate, we have obtained concentric ring-banded structures in thin films of poly(L-lactic acid) and the electroactive polyamide blends when the content of PLLA is above $80 \mathrm{wt} \%$ in the blends. By contrasting the vertical distance between the lowest and the 
highest points on the surface of blend films and the etched films, we concluded that the bright rings in the ring-banded spherulites in AFM height images are mainly composed of the poly(L-lactic acid). In addition, the crystallization mechanism was also discussed.

Acknowledgment. The authors thank Prof. X. S. Chen at the State Key Laboratory of Polymer Physics and Chemistry of the Changchun Institute of Applied Chemistry for kindly providing the PLLA samples. The financial support from the National Natural Science Foundation of China (NNSFC-20674027) and the National Major Project for Fundamental Research of China (National 973 Program No 2007CD936203 and National 863 Program No 2007AA03Z324) is greatly appreciated.

Received: July 2, 2008 Accepted: August 24, 2008 Published: October 8, 2008

\section{REFERENCES}

1. A. C. Albertsson and I. K. Varma, Biomacromolecules, 4, 1466 (2003).

2. O. Dechy-Cabaret, B. Martin-Vaca, and D. Bourissou, Chem. Rev., 104, 6147 (2004).

3. G. C. Eastmond, Adv. Polym. Sci., 59, 149 (2000).

4. M. Gazzano, M. L. Forcarete, C. Riekel, and M. Scandola, Biomacromolecules, 5, 553 (2004).

5. I. W. Hamley, P. Parras, V. Castelletto, R. V. Castillo, A. J. Müller, E. Pollet, P. Dubois, and C. M. Martin, Macromol. Chem. Phys., 207, 941 (2006).

6. J. Xu, B. H. Guo, J. J. Zhou, L. Li, J. Wu, and M. Kowalczuk, Polymer, 46, 9176 (2005).

7. M. Yasuniwa, S. Tsubakihara, K. Iura, Y. Ono, Y. Dan, and K. Takahashi, Polymer, 47, 7554 (2006).
8. M. L. Focarete, G. Ceccorulli, M. Scandola, and M. Kowalczuk, Macromolecules, 31, 8485 (1998).

9. I. Ohkoshi, H. Abe, and Y. Doi, Polymer, 41, 5985 (2000).

10. C. Nakafuku, Polym. J., 28, 568 (1996).

11. J. M. Yang, H. L. Chen, J. W. You, and J. C. Hwang, Polym. J., 29, 657 (1997)

12. K. S. Kim, I. J. Chin, J. S. Yoon, H. J. Choi, D. C. Lee, and K. H. Lee, J. Appl. Polym. Sci., 82, 3618 (2001).

13. A. Keller, J. Polym. Sci., 17, 291 (1955).

14. H. D. Keith and F. J. Padden, J. Polym. Sci., 39, 101 (1959).

15. H. D. Keith, Macromolecules, 15, 114 (1982).

16. R. M. Ho, K. Z. Ke, and M. Chen, Macromolecules, 33, 7529 (2000)

17. P. D. Hong, W. T. Chung, and C. F. Hu, Polymer, 43, 3335 (2002).

18. L. Franco and J. Puiggali, J. Polym. Sci., Part B: Polym. Phys., 40, 1719 (2002).

19. J. K. Lee, M. J. Choi, J. E. Im, D. J. Hwang, and K. H. Lee, Polymer, 48, 2980 (2007).

20. C. Y. Ko, M. Chen, C. L. Wang, H. C. Wang, R. Y. Chen, and I. M. Tseng, Polymer, 48, 2415 (2007).

21. A. Keller, Nature (London), 31, 913 (1952).

22. A. Keller, J. Polym. Sci., 39, 151 (1959).

23. Z. Wang, L. An, B. Jiang, and X. Wang, Macromol. Rapid. Commun., 19, 131 (1998).

24. Y. Okabe, T. Kyu, H. Saito, and T. Inoue, Macromolecules, 31, 5823 (1998).

25. T. Kyu, H. W. Chiu, A. J. Guenther, Y. Okabe, H. Saito, and T. Inoue, Phys. Rev. Lett., 83, 2749 (1999).

26. J. Chen and D. C. Yang, Macromol. Rapid. Commun., 25, 1425 (2004).

27. Y. X. Duan, Y. Jiang, S. D. Jiang, L. Li, S. K. Yan, and J. M. Schultz, Macromolecules, 37, 9283 (2004).

28. Z. B. Wang, Z. J. Hu, Y. Z. Chen, Y. M. Gong, H. Y. Huang, and T. B. He, Macromolecules, 40, 4381 (2007).

29. D. M. Chao, X. B. Ma, X. F. Lu, L. L. Cui, H. Mao, W. J. Zhang, and Y. Wei, J. Appl. Polym. Sci., 104, 1603 (2007).

30. D. M. Chao, X. F. Lu, J. Y. Chen, X. C. Liu, W. J. Zhang, and Y Wei, Polymer, 47, 2643 (2006).

31. X. C. Liu, D. Wang, W. J. Zhang, and D. C. Yang, Chem. J. Chin. Univ., 27, 1392 (2006). 